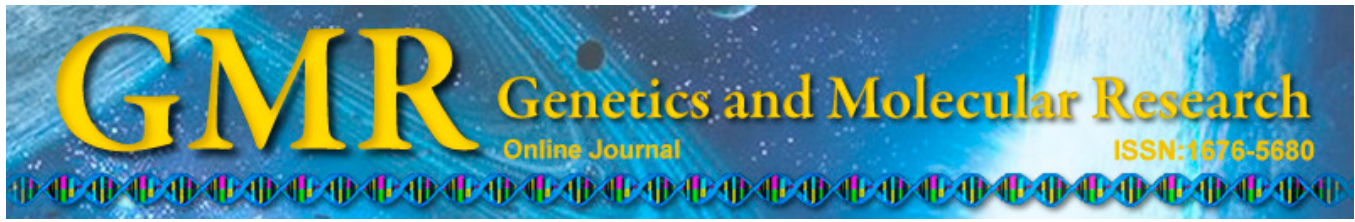

\title{
Evaluation of reference genes for RT-qPCR studies in the leaves of rice seedlings under salt stress
}

\author{
G.P. Moraes ${ }^{1}$, L.C. Benitez ${ }^{1}$, M.N. do Amaral ${ }^{1}$, I.L. Vighi' ${ }^{1}$, P.A. Auler ${ }^{1}$, \\ L.C. da Maia ${ }^{2}$, V.J. Bianchi ${ }^{1}$ and E.J.B. Braga ${ }^{1}$ \\ ${ }^{1}$ Departamento de Botânica, Universidade Federal de Pelotas, \\ Pelotas, RS, Brasil \\ ${ }^{2}$ Departamento de Fitotecnia, Universidade Federal de Pelotas, \\ Pelotas, RS, Brasil \\ Corresponding author: G.P. Moraes \\ E-mail: gabriela.moraes.freitas@gmail.com
}

Genet. Mol. Res. 14 (1): 2384-2398 (2015)

Received June 11, 2014

Accepted October 29, 2014

Published March 27, 2015

DOI http://dx.doi.org/10.4238/2015.March.27.24

ABSTRACT. To obtain accurate and reliable results for the expression
of genes of interest using quantitative real-time polymerase chain
reaction (RT-qPCR) techniques, it is necessary to normalize the data by
comparing them to constitutive genes that exhibit uniform expression
levels under experimental conditions. In this study, the stability of
expression was evaluated for the following ten candidate reference
genes in rice leaves (Oryza sativa L.) from the BRS Bojuru and BRS
Ligeirinho genotypes that were subjected to salt stress (150 mM):
actin 11 ( $A C T 11)$, beta-tubulin ( $\beta$-TUB), eukaryote elongation factor
$1-\alpha(E e f-1)$, eukaryotic initiation factor $4-\alpha$ ( $I F-4-\alpha)$, E2 ubiquitin-
conjugating enzyme (UBC-E2), ubiquitin 5 (UBQ5), ubiquitin 10
(UBQ10), glyceraldehyde-3-phosphate dehydrogenase (GAPDH),
TIP41-like, and cyclophilin. The stability of expression for the
aforementioned genes was then compared to that of three $L T P$ genes
using $U B Q 10, E e f-1$, and $e I F-4-\alpha$ as references. After analyzing the 
expression levels using analysis of variance tests, the results indicated that $U B Q 10$ was the most stable in all treatments $(\mathrm{M}=0.404$ and $\mathrm{SV}$ $=0.327)$. Furthermore, the eIF-4- $\alpha$, TIP41-like, and cyclophilin genes exhibited the highest total coefficient of variation $(\mathrm{CV}=269,169.2$, 179.2 , respectively), which signifies that they exhibited the least stable expression. The expression levels of each candidate gene (LTP7, $L T P 10$, and LTP13) were in contrast to the reference genes. Therefore, we concluded that $U B Q 10$ is the best reference gene for RT-qPCR reactions under the experimental conditions. The expression analysis of LTP7, LTP 10, and LTP13 confirmed the importance of validating reference genes to achieve accurate RT-qPCR results.

Key words: Oryza sativa L.; Salinity; Ubiquitin; Real-time quantitative PCR

\section{INTRODUCTION}

The production of rice (Oryza sativa L.), like any other crop, can be strongly influenced by several environmental factors. Drought, heat, salinity, UV radiation, and hormones induce numerous physiological stress reactions in plants that alter the chemical composition of crops and the quality of the harvested products (Wang and Frei, 2011). Among the abiotic factors, soil and irrigation water salinity are major problems for irrigated agriculture in many parts of the world. According to data from the Food and Agriculture Organization of the United Nations (FAO, 2008), approximately $20 \%$ of cultivated lands have salinization problems. Physiologically, salt stress inhibits the growth and development of plants, which reduces the osmotic potential of the soil solution, restricts water availability, and/or accumulates excess ions in plant tissues. These effects can cause ion toxicity, nutritional imbalance, or both (Tester and Davenport, 2003). Other consequences of salinity involve disturbances to membrane integrity (Eraslan et al., 2007), variations in growth regulator levels (Iqbal et al., 2014), and changes in metabolic activity. Moreover, the changes in metabolic activity may include photosynthesis modifications (Marín-Guirao et al., 2011), increased production of reactive oxygen species, and fluctuations in the concentrations of total soluble carbohydrates, total phenols, glycine betaine, proline, chlorophyll, and proteins (Panda and Khan, 2009).

Rice is typically classified as being sensitive to soil salinity (Munns and Tester, 2008) with decreases in productivity occurring at electrical conductivity values of $3.0 \mathrm{dS} / \mathrm{m}$ (deciSiemens per meter), which corresponds to losses of $12 \%$ for each $\mathrm{dS} / \mathrm{m}$ above the tolerable threshold (Maas, 1993). Several rice studies have used strategies that allow the identification of genes expressed in response to different treatment and/or stress conditions (Walia et al., 2005). However, in these experiments, it is necessary to select several candidate genes that must be validated with specific analyses to quantify their expression in response to stress. Quantitative reverse transcription PCR (RT-qPCR) is a widely used molecular biology technique for the validation of gene expression data because of its sensitivity and reproducibility in transcript analyses. The technique is based on the process of reverse transcription (RT), followed by DNA PCR with fluorescent tag molecules covalently bonded to the nucleotides of the synthesized amplicon. The products formed are monitored during each cycle of the reaction, allowing for the rapid and accurate detection of amplified cDNA (Gachon et al., 2004). However, this technique requires standardization to correctly interpret the data obtained. Stan- 
dardization is performed by analyzing the expression of target genes simultaneously with one or more constitutive genes that exhibit constant and uniform expression in most cells, during all developmental stages, and under different experimental conditions. Without this standardization, incorrect results may be obtained (Jain et al., 2006). These constitutive genes are termed reference, normalizer, or standard genes in the RT-qPCR technique (de Oliveira et al., 2012).

Sequences from both the constitutive gene and the gene of interest (target) will be present in the tested sample. However, the constitutive gene should not exhibit significant variation in expression because it is a reference gene, but the target may have different expression patterns within the experiment (Expósito-Rodríguez et al., 2008). The genes chosen as references are usually involved in basic cellular processes such as cell structure maintenance and primary metabolism (Czechowski et al., 2005; de Oliveira et al., 2012). Although several genes are routinely used and reported as good reference genes in studies with plants, the genes encoding 18S rRNA (18S rRNA), glyceraldehyde-3-phosphate dehydrogenase $(G A P D H)$, elongation factor $1 \alpha(E F-1 \alpha)$, actin $(A C T)$, and $\alpha$ tubulin $(\alpha$-TUB) (Benitez et al., 2013) have shown differential expression between tissues, genotypes, and ambient test conditions (Czechowski et al., 2005; Expósito-Rodríguez et al., 2008; Gutierrez et al., 2008). The use of inappropriate reference genes radically changes the interpretation of the expression pattern of a given target gene and introduces flaws into our understanding of the role of the gene. Therefore, the lack of reference gene validation in plants compromises the accuracy of results obtained by RT-qPCR protocols that use non-valid references (Gutierrez et al., 2008). To evaluate the stability of reference gene expression, several algorithms have been developed in recent years, including those used in the geNorm and NormFinder programs (Silver et al., 2006). The algorithm of the geNorm program indicates the two most stable reference genes or multiple combinations of various stable genes by calculating the average expression stability (M) based on the arithmetic mean of the number of candidate reference genes compared pairwise (Vandesompele et al., 2002). This tool uses the principle that the expression ratio of two perfect reference genes should remain constant across different experimental treatments. The algorithm of the NormFinder program identifies the best reference gene in a group of candidate genes based on their expression stability. This algorithm evaluates the total variation in the expression of the candidate genes using the sum of variance (Andersen et al., 2004).

Therefore, we evaluated the stability of gene expression to identify potential reference genes with stable expression for RT-qPCR studies in the leaves of rice seedlings under salt stress. Furthermore, differences in the expression levels of 10 reference genes were revealed using comparisons of serial analyses with three LTP (lipid transfer protein) genes, which were previously identified as being responsive to salt stress.

\section{MATERIAL AND METHODS}

\section{Plant material and experimental conditions}

Rice seeds (Oryza sativa L.) from the BRS Bojuru (salt-tolerant) and BRS Ligeirinho (salt-sensitive) genotypes were disinfected with $1 \%$ hypochlorite, germinated on Germitest paper in transparent plastic boxes (Gerbox $\left.{ }^{\circledR}, \mathrm{BRA}\right)$, and kept in a biological organism development (BOD) growth chamber with a 12 hour photoperiod at $25^{\circ} \pm 2{ }^{\circ} \mathrm{C}$ for 10 days. After this period, the seedlings were transferred into plastic pots $(500 \mathrm{~mL})$ containing sand as the substrate, which was previously washed with $1 \%$ hydrochloric acid. The seedlings were irrigated 
every two days with water and Hoagland and Arnon (1938) nutrient solution in a greenhouse. Upon reaching the $\mathrm{V}_{4}$ (four leaves) growth stage, plants underwent alternating irrigation with nutrient solution and water containing $150 \mathrm{mM} \mathrm{NaCl}(100 \mathrm{~mL} /$ pot $)$. The $\mathrm{NaCl}$ concentration was chosen based on data from reported experiments that examined saline stress in rice (Abbas et al., 2013). After the experiment was established, leaves of rice seedlings were collected every 24 hours, and were identified as $\mathrm{C} 1, \mathrm{C} 2, \mathrm{C} 3, \mathrm{C} 4$, and $\mathrm{C} 5$ based on the following criteria: $\mathrm{C} 1=$ plants with no exposure to stress (control); $\mathrm{C} 2=24 \mathrm{~h}$ of stress; $\mathrm{C} 3=48 \mathrm{~h}$ of stress; $\mathrm{C} 4$ $=72 \mathrm{~h}$ of stress; $\mathrm{C} 5=96 \mathrm{~h}$ of stress in a $150 \mathrm{mM} \mathrm{NaCl}$ solution. The experimental design was completely randomized, according to a factorial 2 × 5 ( 2 genotypes $\times 5$ evaluation times), and used three biological replicates that included five plants each in three replicate pots.

\section{Total RNA extraction and cDNA synthesis}

Total RNA was extracted from $100 \mathrm{mg}$ of leaves according to the manufacturer protocol for (Plant RNA Reagent Purilink ${ }^{\circledR}$, USA). RNA quantity and purity were determined using a NanoDrop ND-1000, and RNA quality and integrity were verified via electrophoresis on a $1.0 \%$ agarose gel. The single-stranded cDNAs were synthesized by reverse transcription from $2 \mu \mathrm{g}$ of total RNA using oligo dT primer and the SuperScript First-Strand Synthesis System for RT-PCR Kit (Invitrogen ${ }^{\circledR}-18080093$, USA).

\section{Selection of the reference and candidate genes}

Ten genes that were cited in the literature as internal controls for RT-qPCR analyses, which supposedly exhibit no significant differences between treatments, were selected as possible reference genes (Table 1).

Table 1. Description of the candidate reference genes for the qRT-PCR reactions in rice plants under salt stress.

\begin{tabular}{|c|c|c|c|c|c|}
\hline Gene & Accession & F: Primer $\left(5^{\prime}-3^{\prime}\right)$ & R: Primer (5'-3') & $\begin{array}{l}\text { Average } \\
\text { efficiency }\end{array}$ & References \\
\hline ACT11 & AK100267 & CAGCCACACTGTCCCCATCTA & AGCAAGGTCGAGACGAAGGA & 2.02 & Zhang and $\mathrm{Hu}(2009)$ \\
\hline$\beta$-Tubulin & AK072502 & GCTGACCACACCTAGCTTTGG & AGGGAACCTTAGGCAGCATGT & 1.90 & Zhang and $\mathrm{Hu}(2009)$ \\
\hline Eef- $1 \alpha$ & AK061464 & TTTCACTCTTGGTGTGAAGCAGAT & Г GACTTCCTTCACGATTTCATCGTAA & 1.96 & Zhang and $\mathrm{Hu}(2009)$ \\
\hline$U B C-E 2$ & AK059694 & CCGTTTGTAGAGCCATAATTGCA & AGGTTGCCTGAGTCACAGTTAAGTG & $\mathrm{G} 2.13$ & Jain et al. (2006) \\
\hline$e I F-4-\mathrm{a}$ & AK073620 & TTGTGCTGGATGAAGCTGATG & GGAAGGAGCTGGAAGATATCATAGA & A 2.05 & Jain et al. (2006) \\
\hline$U B Q 10$ & AK101547 & TGGTCAGTAATCAGCCAGTTTGG & GCACCACAAATACTTGACGAACAG & 1.96 & Jain et al. (2006) \\
\hline$U B Q 5$ & AK061988 & ACCACTTCGACCGCCACTACT & ACGCCTAAGCCTGCTGGTT & 2.00 & Jain et al. (2006) \\
\hline$G A P D H$ & AK064960 & AAGCCAGCATCCTATGATCAGATT & CGTAACCCAGAATACCCTTGAGTTT & 1.93 & Jain et al. (2006) \\
\hline TIP41 - like & AK103511 & GTTTGGATGAACCCCGCAA & GGCAACAAGGTCAATCCGATC & 1.95 & Caldana et al. (2007) \\
\hline cyclophilin & AK121304 & CCACCATCACAGATCGGATCTT & GCGGTCAGAGCGAAAGTAGCTA & 2.00 & Caldana et al. (2007) \\
\hline LTP7 & AK058896 & GGAGGGTGTGACATCGCAGG & AAGCGTGAGACGACGACAGGT & 2.08 & - \\
\hline LTP10 & AK061288 & ATTAACCAACACCGAGCATCA & CGATCGATCCAGAGGATGCTA & 2.09 & - \\
\hline$L T P 13$ & CU406598 & CTTCTTGTTGCTGAGGCAATCTG & TTATGGGACGGAGGGAGTAGAG & 2.07 & - \\
\hline
\end{tabular}

The genes selected were actin11 (ACT11), ubiquitin conjugating enzyme E2 (UBC$E 2)$, eukaryotic elongation factor1- $\alpha(E e f-1 \alpha)$, glyceraldehyde-3-phosphate dehydrogenase $(G A P D H), \beta$-tubulin ( $\beta$-Tub), eukaryotic initiation factor 4a (Eif-4- $\alpha)$, ubiquitin10 (UBQ10), ubiquitin5 (UBQ5), aquaporin TIP41 (TIP41-like), and cyclophilin.

Sequences of candidate genes (LTP7, LTP10, and LTP13) in rice that code for LTP proteins were obtained from the RAP-DB database (http://rapdb.dna.affrc.go.jp/). These three 
candidate genes were considered responsive to salt stress according to the Microarrays Genevestigator database (https://www.genevestigator.com/gv/) and GEO Profile (https://www.ncbi. nlm.nih.gov/geoprofiles).

An alignment analysis of the nucleotide sequences of possible $L T P$ isoforms present in the rice genome was performed to guarantee primer specificity. Three pairs of specific oligonucleotide primers were designed based on the deduced nucleotide sequence from putative LTP transcripts using the Primer Express v.3.0 and BioEdit v.7.0 software (complementary information about reference genes and candidate gene primers are presented in Table 1).

\section{Specificity and efficiency standard curves}

The specificity and efficiency standard curves of the primers were evaluated from a pool of 15 cDNAs ( 5 times $x 3$ repetitions) for each genotype. Initially, the specificity of each primer set was found by the dissociation (melting) curve, and only those primers with specific amplicons were retained in this study (i.e., those with a single dissociation peak of the PCR products).

PCR efficiency (E) was obtained from four serial dilutions of cDNA $(1: 1,1: 5,1: 25$, and 1:125) to generate a standard curve for each primer set tested. The value of $E$ was calculated according to the equation of Rasmussen (2001), where the slope corresponds the slope of the regression line between the $\mathrm{C}_{\mathrm{T}}$ values (cycle threshold) of the transcripts and the values of the logarithms of different cDNA dilutions (efficiency standard curve). Efficiency values between 1.8 and 2.2 were considered acceptable, which corresponds to a reaction efficiency of $90-110 \%$. The amplification efficiency of each primer pair was calculated individually for the genotypes and used to obtain the average efficiency. All primers functioned at an annealing temperature of $60^{\circ} \mathrm{C}$, and the reactions were performed in triplicate for each cDNA dilution.

\section{Stability of the reference genes}

To test the stability of the reference genes, changes in the expression levels of samples exposed to 24, 48, 72, and 96 hours of salt stress were compared to control samples (no stress). The formula used to calculate the stability was similar to the one proposed by Chao et al. (2012), where:

$$
\Delta \mathrm{C}_{\text {TsampleN }}=\mathrm{C}_{\text {TsampleN }}-\mathrm{C}_{\text {Tcontrol }}
$$

(Equation 1)

From the $\Delta \mathrm{C}_{\mathrm{T}}$ values obtained, the relative quantification (RQ) values were calculated using the modified formula of Pfaffl et al. (2002). The RQ values were subjected to analysis of variance (ANOVA) tests ( $\mathrm{rroc} \mathrm{glm}$ ) to identify possible variation based on the genotype and time of collection. Factors of the F-test with values of $\mathrm{P} \leq 0.05$ were considered to be statistically significant. Subsequently, using the proc univariate routine, additional information was obtained regarding the overall mean (means), standard deviation (SD), and coefficient of variation $(\mathrm{CV} \%)$ of different genotypes. Additionally, the total $\mathrm{SD}$ and $\mathrm{CV} \%$ values were calculated for each candidate reference gene. Statistical analyses were performed using SAS v.9.3 (2012, SAS Institute Inc., Cary, NC, USA). Reference genes were considered stable when the ANOVA found no significant difference in the time of exposure to salt stress factors as well as no interaction, and genes with smaller SD and $\mathrm{CV} \%$ values were also considered stable. 
In parallel with the statistical analyses, the stability of the reference genes for both genotypes was assessed using the RefFinder tool available at http://www.leonxie.com/, which includes the geNorm and NormFinder computational algorithms to compare and classify the stability of the candidate reference genes. The $\mathrm{C}_{\mathrm{T}}$ values for each gene were utilized by these algorithms to determine their relative expression stability.

\section{RT-qPCR reactions}

The total volume of the RT-qPCR reactions was $12 \mu \mathrm{L}$, consisting of $6.25 \mu \mathrm{L}$ SYBR green fluorophore (Applied Biosystems ${ }^{\circledR}$, USA), $0.25 \mu \mathrm{L} 10 \mathrm{mM}$ of each primer (forward and reverse), $1 \mu \mathrm{L}$ cDNA (1:25 dilution, previously defined), and $4.25 \mu \mathrm{L}$ ultrapure water. The reactions were run on a (Bio-Rad CFX Real Time Thermal Cycler, USA) using the following amplification conditions: $95^{\circ} \mathrm{C}$ for 10 minutes, followed by 40 cycles of $95^{\circ} \mathrm{C}$ for 15 seconds, $60^{\circ} \mathrm{C}$ for 1 minute, and $72^{\circ} \mathrm{C}$ for 1 minute with the insertion of the melting curve of $65-95^{\circ} \mathrm{C}$, with an increment of $5^{\circ} \mathrm{C}$ for each fluorescence measurement. For each biological replicate, three technical replicates (triplicates) were performed.

\section{RESULTS}

The amplification specificity is determined by the presence of a single peak along the dissociation (melting) curve. At the end of the reaction, the fluorescence of the samples, relative to the continuous increase in temperature, is analyzed along this curve. Furthermore, each amplicon has a specific melting temperature, which makes it possible to differentiate the PCR products. The dissociation curves shown in Figures S1 and S2 indicate that after 40 amplification cycles, all primers used in this study have a well-defined single peak, confirming the specificity of the amplified product.

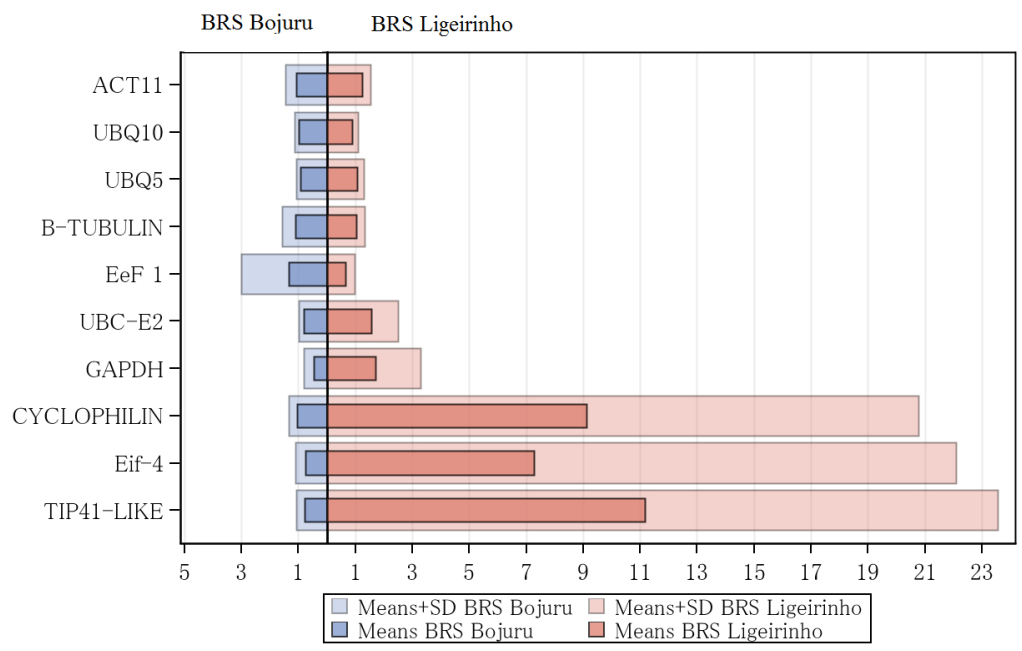

Figure 1. Relative quantification (RQ) and standard deviation (SD) of expression data for ten candidate reference genes that were analyzed using cDNA from the leaves of BRS Bojuru and BRS Ligeirinho rice genotypes after different exposures to $150 \mathrm{mM} \mathrm{NaCl}$. 

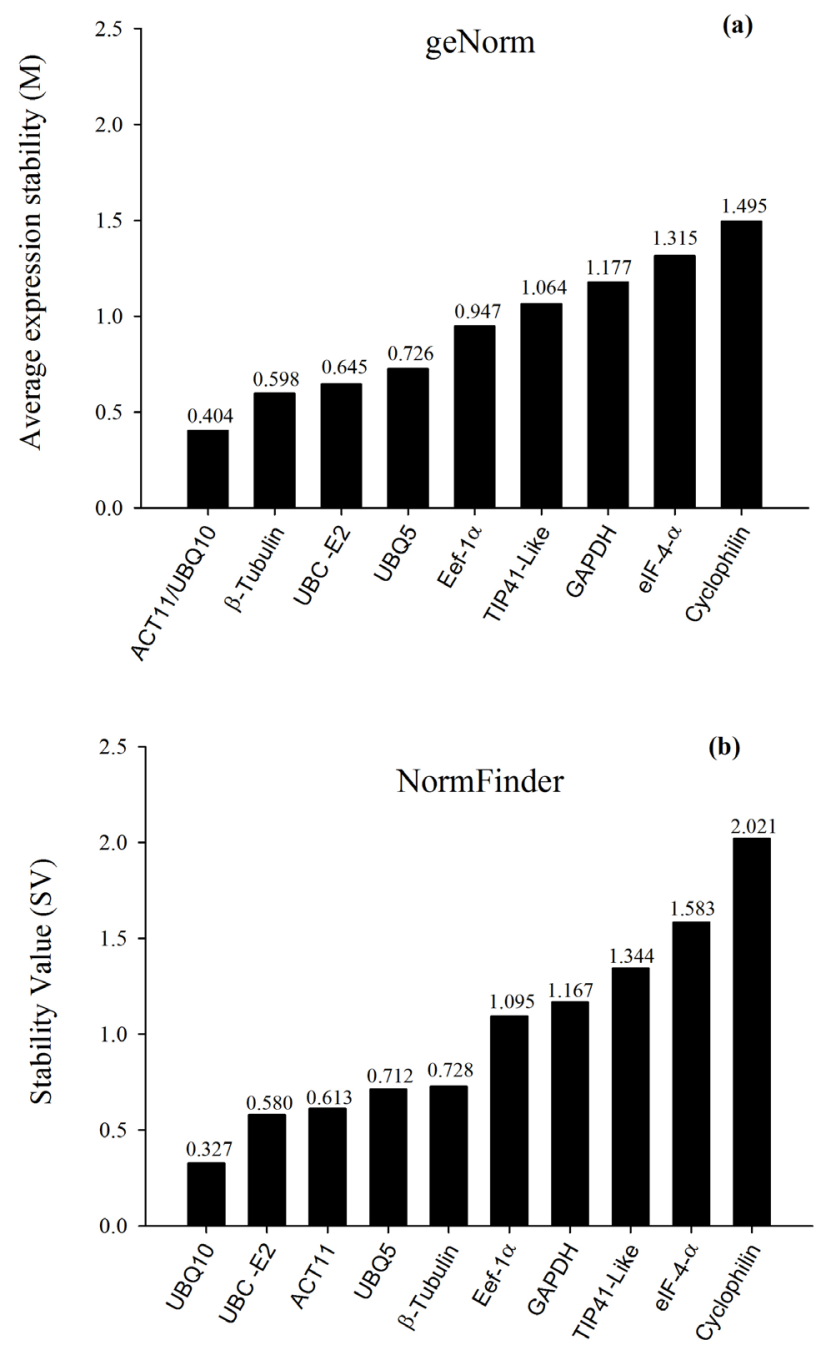

Figure 2. Average expression stability (M) according to the geNorm (a) and the stability value (SV) according to the NormFinder (b) algorithms for ten candidate reference genes that were analyzed using cDNA from the leaves of BRS Bojuru and BRS Ligeirinho rice genotypes after different exposures to $150 \mathrm{mM} \mathrm{NaCl}$.

The efficiency of primer amplification was individually calculated from the logarithm $(\log )$ of cDNA dilutions for each genotype, and efficiencies near $100 \%$ were observed (ranging between 1.85 and 2.16). This finding indicates that at the end of each cycle, the transcribed template was duplicated with $10 \%$ variation, which does not significantly influence the results (Figures S1 and S2).

According to the ANOVA, there was a significant interaction and an isolated effect of the factors (genotype and exposure to salt stress) for Eef-1 $\alpha, e I F-4 \alpha, G A P D H$, TIP4-like, and cyclophilin reference genes, which demonstrates that these genes exhibit variation in their RQ values according to the genotype and stress exposure time. Regarding $U B C$-E2, a significant 
effect was only observed for the qualitative factor (genotype); however, no significant effect was found for any of the factors associated with ACT11, $\beta$-Tubulin, UBQ10, and UBQ5.

The SD and $\mathrm{CV} \%$ values clearly indicate that $U B Q 10$ had the lowest total SD (0.18) and $\mathrm{CV} \%$ (18.52) values among the tested reference genes, and this was followed by UBQ5 and $A C T 11$, which indicates greater expression stability for these genes (Table 2).

Table 2. Overall mean (means), standard deviation (SD), and coefficient of variation (CV\%) of the expression data for ten candidate reference genes that were analyzed using cDNA from the leaves of BRS Bojuru and BRS Ligeirinho rice genotypes after different exposures to $150 \mathrm{mM} \mathrm{NaCl}$.

\begin{tabular}{|c|c|c|c|c|c|c|c|c|c|c|c|}
\hline & & ACT11 & $\beta$-TUB & Eef-1 $1 \alpha$ & $U B C-E 2$ & $e I F-4-\alpha$ & $U B Q 10$ & $U B Q 5$ & $G A P D H$ & TIP41- & Cyclophilin \\
\hline \multirow{4}{*}{ Means } & BRS Bojuru & 1.08 & 1.11 & 1.32 & 0.81 & 0.76 & 0.97 & 0.91 & 0.46 & 0.77 & 1.04 \\
\hline & BRS Ligeirinho & 1.23 & 1.03 & 0.66 & 1.58 & 7.28 & 0.90 & 1.08 & 1.71 & 11.17 & 9.11 \\
\hline & Overall & 1.15 & 1.07 & 0.99 & 0.90 & 4.02 & 0.94 & 1.00 & 1.09 & 5.97 & 5.07 \\
\hline & BRS Bojuru & 0.38 & 0.46 & 1.67 & 0.17 & 0.33 & 0.15 & 0.17 & 0.35 & 0.29 & 0.29 \\
\hline \multirow[t]{3}{*}{$\mathrm{SD}$} & BRS Ligeirinho & 0.31 & 0.30 & 0.33 & 0.91 & 14.82 & 0.19 & 0.23 & 1.57 & 12.39 & 11.68 \\
\hline & Total SD & 0.35 & 0.39 & 1.23 & 0.75 & 10.00 & 0.18 & 0.22 & 1.29 & 10.10 & 9.10 \\
\hline & BRS Bojuru & 35.19 & 41.89 & 126.00 & 21.75 & 43.38 & 15.35 & 18.78 & 76.75 & 31.37 & 23.71 \\
\hline \multirow[t]{2}{*}{$\mathrm{CV} \%$} & BRS Ligeirinho & 25.62 & 29.83 & 49.60 & 57.55 & 203.00 & 21.35 & 21.87 & 91.91 & 110.92 & 128.22 \\
\hline & Total CV & 30.41 & 36.44 & 123.90 & 63.04 & 269.00 & 18.52 & 21.91 & 118.22 & 169.22 & 179.22 \\
\hline
\end{tabular}

In contrast, TIP41-like, Eif-4 $\alpha$, and the cyclophilin gene had SD values between 9.10 and 10.10 and CV\% values between 169.22 and 269.00. It was also apparent that there was greater variation in the expression stability of genes from the salt stress-sensitive BRS Ligeirinho genotype, with the exception of the Eef-1 $\alpha$ gene, which exhibited higher SD values in the BRS Bojuru genotype (Figure 1).

To evaluate the stability of candidate gene expression, in addition to the ANOVA, the average expression stability (M) and the stability value (SV) were calculated and compared using the geNorm and NormFinder algorithms, respectively. The geNorm program is based on the principle that the expression ratio of two reference genes should remain constant across different experimental conditions and/or organs or tissues. The $\mathrm{M}$ value is defined as the average variation of a particular gene compared to all others tested. Based on the $\mathrm{M}$ values calculated for the ten genes, it was observed that $A C T 11 / U B Q 10(\mathrm{M}=0.404)$ were the most stable genes, whereas $\beta$-Tubulin $(\mathrm{M}=0.598)$ GAPDH $(\mathrm{M}=1.177)$, eIF-4-a $(\mathrm{M}=1.315)$, and cyclophilin $(\mathrm{M}=1.495)$ were the most variable genes (Figure 2a).

According the NormFinder results (Figure $2 \mathrm{~b}$ ), the candidate gene with the lowest $\mathrm{SV}$ value was $U B Q 10$ with $\mathrm{SV}=0.327$, followed by $\mathrm{SV}=0.580$ and 0.613 for $U B C$ $E 2$ and $A C T 11$, respectively. The cyclophilin gene $(\mathrm{SV}=2.021)$ had the highest $\mathrm{SV}$ value, followed by eIF-4- $a(\mathrm{SV}=1.583)$ and TIP41-like $(\mathrm{SV}=1.344)$. These data are similar to those found in the ANOVA and geNorm analyses, and this is explained by the fact that these analyses took the relative expression values calculated from the $\mathrm{C}_{\mathrm{T}}$ values into account. The determination of a suitable reference gene for gene expression studies is the first step that allows the analysis of relative expression patterns in genes of interest, thus providing more reliable results. In order to validate the stability of reference genes, the relative expression profiles were analyzed for the following genes: UBQ10 (more stable according to SD intervals), Eef- $1 \alpha, G A P D H$ (intermediate stability), $e I F-4-\alpha$ (slightly stable), and the three target genes ( $L T P 7, L T P 10$ and $L T P 13)$. When the more stable reference gene (UBQ10) was used to validate the stability in the leaves of rice plants exposed to $\mathrm{NaCl}$ stress, the expression of LTP7 increased 13.8-fold in the tolerant genotype and 8.03-fold in the sensitive genotype after $96 \mathrm{~h}$ 
of exposure to stress compared to control plants (Figure 3a).
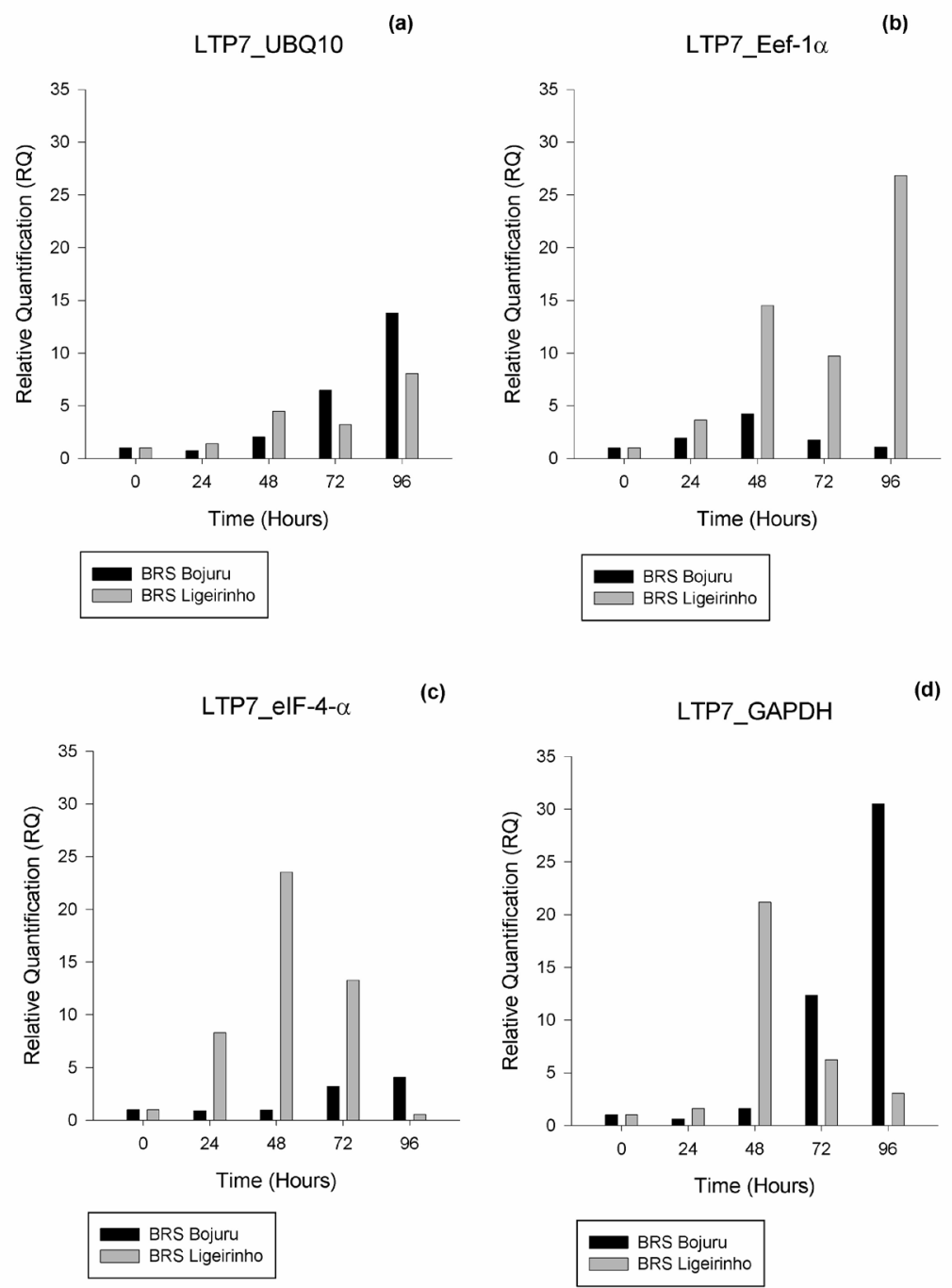

Figure 3. Real-time quantitative PCR analysis of $L T P 7$ gene expression in the leaves of rice genotypes, BRS Bojuru and BRS Ligeirinho, that were differentially exposed to $150 \mathrm{mM} \mathrm{NaCl}$. UBQ10, Eef-1 $\alpha$, Eif-4- $\alpha$, and GAPDH were used as reference genes.

These expression patterns were modified when the RQ values were measured using the other reference genes. For instance, $\mathrm{RQ}=30.51$ for the tolerant genotype at $96 \mathrm{~h}$ of exposure using GAPDH as a reference (Figure 3b-d). Similar results were observed when LTP10 expression was evaluated, and the largest variation was observed in the sensitive genotype at $96 \mathrm{~h}$ of exposure to salt stress. In comparison to the expression of LTP10, the expression value was 71.10-fold for $U B Q 10$, whereas a RQ $=517.56$ was registered for Eef- $1 \alpha$ (Figure 4a and b). 

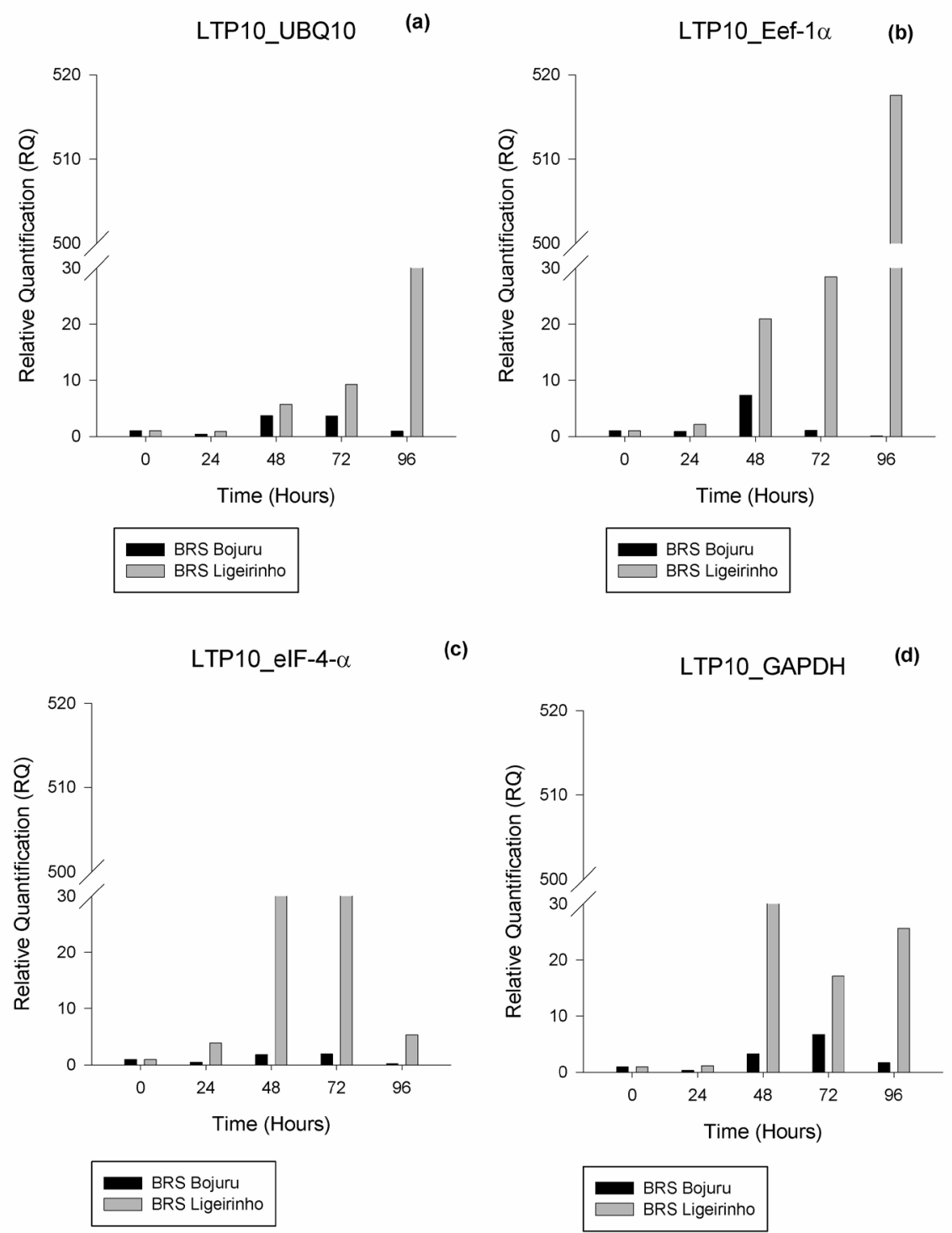

Figure 4. Real-time quantitative PCR analysis of $L T P 10$ gene expression in the leaves of rice genotypes, BRS Bojuru and BRS Ligeirinho, that were differentially exposed to $150 \mathrm{mM} \mathrm{NaCl}$. UBQ10, Eef-1 $\alpha$, Eif-4- $\alpha$, and $G A P D H$ were used as reference genes.

Thus, inappropriate use of the reference genes gives rise to the misinterpretation of the relative expression profile (Figure $4 \mathrm{c}$ and d). Evaluating the expression of the target gene $L T P 13$ relative to reference genes, we observed variations when the more stable gene $(U B Q 10)$ was used. Variations were also detected when the least stable reference genes for both genotypes (Figure 5a-d) were used, which further corroborates the importance of validating reference genes before experimental applications. 
LTP13_UBQ10
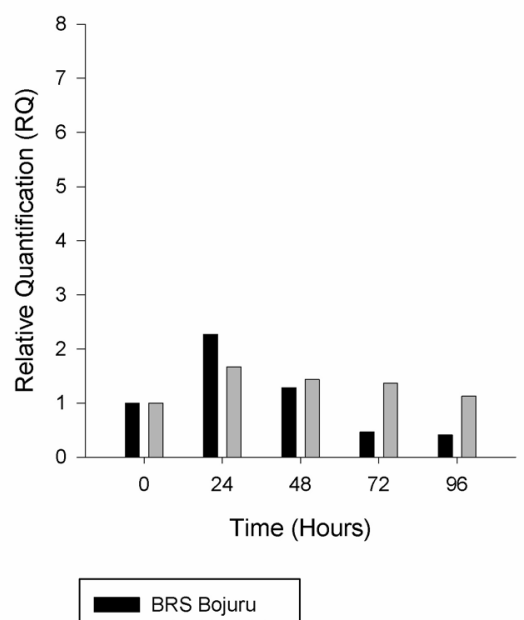
$\square$ BRS Ligeirinho

LTP13_elF-4- $\alpha$

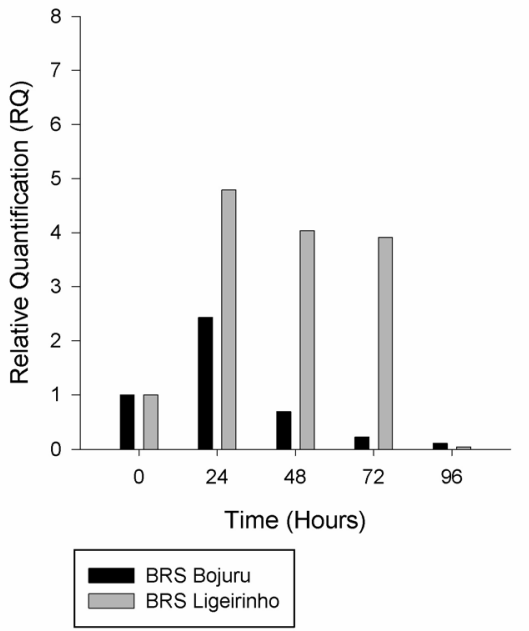

(c)
LTP13_Eef-1 $\alpha$

(b)

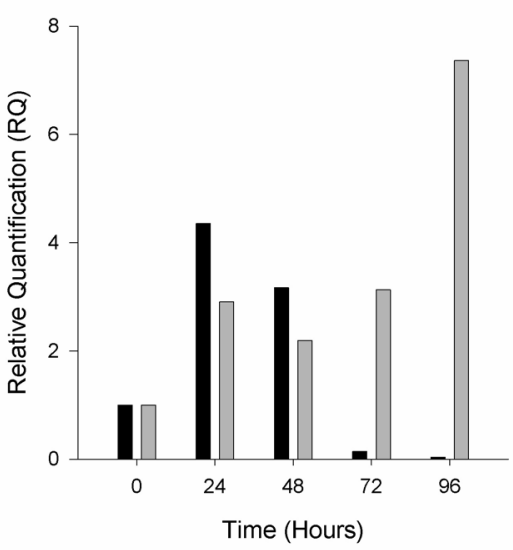

BRS Bojuru $\square$ BRS Ligeirinho

LTP13_GAPDH

(d)

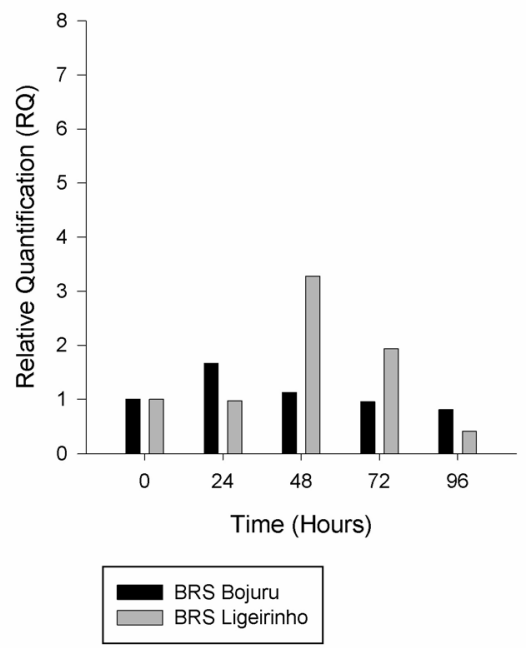

Figure 5. Real-time quantitative PCR analysis of $L T P 13$ gene expression in the leaves of rice genotypes, BRS Bojuru and BRS Ligeirinho, that were differentially exposed to $150 \mathrm{mM} \mathrm{NaCl}$. UBQ10, Eef-1 $\alpha$, Eif-4- $\alpha$, and $G A P D H$ were used as reference genes.

\section{DISCUSSION}

In the context of gene expression analysis, the RT-qPCR technique has become one of the most important methods for research on gene expression profiles (Gachon et al., 2004). However, for correct interpretation of the data analyzed, efficient standardization becomes a fundamental condition for reliable results, particularly for verifying the 
biological relevance of minor differences or in the study of samples from different organs or tissues (Expósito-Rodriguez et al., 2008; Gutierrez et al., 2008; Guénin et al., 2009). Several genes are commonly known to be constitutive, and are regularly used as reference genes in RT-qPCR analyses (Wang et al., 2012). However, even genes involved in basic cellular metabolism processes can exhibit significant variations in expression that make them unsuitable as internal controls in certain situations (Czechowski et al., 2005; Gutierrez et al., 2008; Guénin et al., 2009; de Oliveira et al., 2012). The ideal reference gene should have the same expression, regardless of the experimental conditions. Given the concerns about the choice of stable reference genes, this study examined the expression patterns of ten candidate reference genes in the leaves of rice plants after various lengths of salt exposure $(150 \mathrm{mM} \mathrm{NaCl})$. Actin is the most abundant intracellular protein in eukaryotic cells, and it is present in higher concentrations in the cell cortex. Genes encoding actin are commonly used as references in gene expression analyses (Jain et al., 2006; Caldana et al., 2007). In the present study, the $A C T 11$ gene showed a relatively stable pattern of expression, and was considered, along with $U B Q 10$, to be one of the most appropriate reference genes under the experimental conditions. These results are in agreement with those found by Caldana et al. (2007) who identified ACT1 (AK071586) as one of the most stable genes for salt stress experiments that analyzed the expression profiles of rice transcription factors. In contrast, Nicot et al. (2005), suggested that the use of $A C T$ (X55749) as an internal control is inappropriate when studying biotic and abiotic stress in Solanum tuberosum ssp tuberosum L. The results reported above imply that the stability of orthologous actin genes varies in different plant species and under different conditions. Thus, the adequacy of a reference gene must be tested (Zhang and Hu, 2009).

Tubulin is a heterodimeric protein consisting of two highly conserved subunits, $\alpha$ and $\beta$ (Whittaker and Triplett, 1999), and it is the main structural component of microtubules in eukaryotic cells. These microtubules play a critical role in numerous basic processes, such as cell division, intracellular transport, cell movement, morphogenesis, and the maintenance of cell shape (Whittaker and Triplett, 1999). Although it is involved in essential cellular processes, tubulin may not exhibit a constituent pattern in all species. According to the results obtained in the present study, the expression pattern observed for the $\beta$-Tubulin gene was among the five most stable, with total SD $=0.39$ and total $\mathrm{CV} \%=36.44 \%$. Similarly, Brunner et al. (2004) obtained good results using tubulins as reference genes in studies of expression in plants of the genus Populus. In contrast, Expósito-Rodriguez et al. (2008) found that tubulin genes were the least stable genes in studies of different organs and developmental stages in S. lycopersicum. Together, these results suggest that constitutive genes may be regulated differently in different species, organs, and developmental stages of plants. Thus, a reference gene with stable expression in one particular organism may not be suitable as a normalizing gene in another organism under a given set of conditions, requiring its validation before use (Jain et al., 2006).

Ubiquitins are highly conserved proteins in eukaryotes, and are involved in the signaling complexes of other proteins (Sun et al., 1997). These proteins also participate in the structure and transcription of chromatin, DNA repair, the regulation of endocytosis, and protein trafficking (Hernandez-Garcia et al., 2009). Among the genes analyzed in the present study on salt stress, the gene encoding ubiquitin 10 (UBQ10) was among the three most stable genes in the analyses using the geNorm and NormFinder. According to Gutierrez et al. (2008), the values of average expression stability $(\mathrm{M})$ obtained from geNorm algorithms, are considered stable when $\mathrm{M}<0.5$. This claim suggests that the $U B Q 10$ gene is the most suitable for use as a reference gene for RT-qPCR analysis in rice plant leaves subjected to $150 \mathrm{mM} \mathrm{NaCl}$, because 
according to geNorm and NormFinder analyses, $\mathrm{M}=0.404$ and $\mathrm{SV}=0.327$, respectively. Furthermore, this gene presented the lowest SD and CV\% values for both BRS Bojuru and BRS Ligeirinho rice genotypes. Corroborating the data obtained, Tong et al. (2009) investigated the expression of 11 reference genes in different samples of Prunus persica, and found that the genes encoding translation elongation factor 2 (TEF2) and ubiquitin 10 (UBQ10) showed stable expression and can be used as reference genes for this species.

Glyceraldehyde-3-phosphate dehydrogenase $(G A P D H)$ is a key enzyme in glycolysis, converting glyceraldehyde-3-phosphate to 1,3-bisphosphoglycerate with concomitant reduction of $\mathrm{NAD}^{+}$to $\mathrm{NADH}_{2}$. In plants, glycolysis occurs in both the cytosol and plastids, and is a fundamental process in the generation of ATP (Muñoz-Bertomeu et al., 2009). The SD and $\mathrm{CV} \%$ values obtained in this study for $G A P D H$ were 1.29 and 118.22 , respectively. These are relatively high values, which indicate the instability of this gene for these specific experimental conditions in rice.

The respiratory pathway plays a crucial role in supplying energy for several metabolic activities in cells. It has been demonstrated that the expression of transcripts corresponding to genes that encode glycolytic enzymes are activated to maintain homeostasis in rice cells under stress conditions, including the lack of $\mathrm{O}_{2}$ (Pareek et al., 1998), which increases the expression and instability of these genes as was observed in this study. Like GAPDH, Eefl- $\alpha$ had a variable expression pattern, with $\mathrm{SD}$ and $\mathrm{CV} \%$ values of 1.23 and 123.90 , respectively. Moreover, geNorm and NormFinder algorithms calculated $\mathrm{M}=0.947$ and $\mathrm{SV}=1.095$, respectively, which differed from the results of Jain et al. (2006) that identified the Eef-1 $\alpha$ gene as one of the most stable in rice tissue samples under different experimental conditions.

Cyclophilins are proteins linked to the function of modulating mitochondrial membrane permeability. Tip41 aquaporins are important transport proteins related to maintaining cellular metabolism. Eukaryotic initiation factors $4 \alpha$ are proteins that are continuously produced in cells and are highly conserved in the eukaryotic genome. These three families of proteins correspond to the cyclophilin, TIP41-like, and eIF-4a genes that were tested in this study. For these genes, higher $\mathrm{SD}, \mathrm{CV} \%$, and average expression stability (M) values were observed, and they were not indicated as reference genes for the experimental conditions tested. Conversely, Caldana et al. (2007) obtained stable expression patterns for these three genes, and they were recommended by the authors as good references for rice plants subjected to $100 \mathrm{mM}$ $\mathrm{NaCl}$. The contradiction of these and other results confirm the importance of correctly choosing the constitutive gene to be used when analyzing the expression of transcripts by RT-qPCR.

To compare the expression pattern of the $U B Q 10$ reference gene, which was identified as the best reference due to its high stability under our experimental conditions, the relative expression of target genes $L T P 7, L T P 10$, and $L T P 13$ were analyzed together with Eef-1 $\alpha$, $G A P D H$, and $e I F-4-\alpha$. Comparing the expression level of $L T P 7$ as a target gene relative to $U B Q 10$, the RQ values increased for both genotypes. However, the expression was higher in the salt tolerant genotype compared to the sensitive genotype. Nevertheless, the same expres-

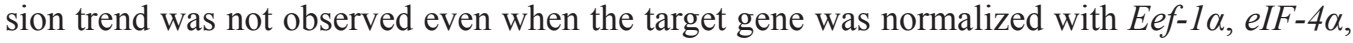
and GAPDH. Contrasting expression levels were also verified for LTP10 and LTP13 target genes based on the reference gene used. The relative expression of $L T P 13$ using UBQ10 as a reference, at all sampling times, did not increase RQ values above 2.3 for either cultivar. However, the RQ values were higher when the reactions were conducted with Eef-1 $\alpha$, followed by $G A P D H$ and $e I F-4 \alpha$ as reference genes.

The necessity for accurate choice of reference genes in studies of expression has been 
confirmed in other studies. For example, when evaluating the expression of $P A L$ and $H P P D$ genes in lettuce plants (Lactuca sativa L.), Borowski et al. (2014) observed significant differences in the expression of these genes depending on both the reference gene and stress condition used. The results of this study confirm the importance of a specific choice of reference genes for transcript analyses by RT-qPCR. As discussed above, erroneous and inconsistent interpretations can occur if prior validation of reference genes is not performed.

\section{CONCLUSIONS}

The analysis of the expression stability of ten candidate reference genes for RT-qPCR studies suggests that the constitutive gene $U B Q 10$ is a suitable gene for studies of rice leaves subjected to salt stress because it exhibited a consistent and continuous expression pattern. In contrast, eIF-4 , cyclophilin, and TIP41-like genes are the least suitable for these experimental conditions. The expression analysis of LTP7, LTP10, and LTP13 confirmed the importance of validating reference genes to achieve accurate RT-qPCR results.

\section{ACKNOWLEDGMENTS}

Research supported by the following Brazilian funding agencies: Coordenação de Aperfeiçoamento de Pessoal de Nível Superior (CAPES), Conselho Nacional de Desenvolvimento Científico e Tecnológico (CNPq), and Fundação de Amparo à Pesquisa do Rio Grande do Sul (FAPERGS).

\section{$\underline{\text { Supplementary material }}$}

\section{REFERENCES}

Abbas MK, Ali SA, Hasan HH and Ghal RH (2013). Salt tolerance study of six cultivars of rice (Oryza sativa L.) during germination and early seedling growth. J. Agr. Sci. 1: 250-259.

Andersen CL, Jensen JL and Orntoft TF (2004). Normalization of real-time quantitative reverse transcription-PCR data: a model-based variance estimation approach to identify genes suited for normalization, applied to bladder and colon cancer data sets. Cancer Res. 64: 5245-5250.

Benitez LC, da Maia LC, Ribeiro MV and Pegoraro C (2013). Salt induced change of gene expression in salt sensitive and tolerant rice species. JAS 5: 251-260.

Borowski JM, Galli V, Messias RS, Perin EC, et al. (2014). Selection of candidate reference genes for real-time PCR studies in lettuce under abiotic stresses. Planta 239: 1187-1200.

Brunner AM, Yakovlev IA and Strauss SH (2004). Validating internal controls for quantitative plant gene expression studies. BMC Plant Biol. 4: 14.

Caldana C, Scheible WR, Roeber BM and Ruzicic S (2007). A quantitative RT-PCR platform for high-throughput expression profiling of 2500 rice transcription factors. Plant Methods 3: 1-7.

Chao WS, Dogramaci M, Foley ME, Horvath DP, et al. (2012). Selection and validation of endogenous reference genes for qRT-PCR analysis in leafy spurge (Euphorbia esula). PLoS One 7: e42839.

Czechowski T, Stitt M, Altmann T, Udvardi MK, et al. (2005). Genome-wide identification and testing of superior reference genes for transcript normalization in Arabidopsis. Plant Physiol. 139: 5-17.

de Oliveira LA, Breton MC, Bastolla FM, Camargo SS, et al. (2012). Reference genes for the normalization of gene expression in eucalyptus species. Plant Cell Physiol. 53: 405-422.

Eraslan F, Inal A, Savasturk O and Gunes A (2007). Changes in antioxidative system and membrane damage of lettuce in response to salinity and boron toxicity. Sci. Hortic. 114: 5-10.

Expósito-Rodríguez M, Borges AA, Borges-Perez A and Perez JA (2008). Selection of internal control genes for quantitative real-time RT-PCR studies during tomato development process. BMC Plant Biol. 8: 131. 
FAO (2008). Extent and Causes Salt-Affected Soils in Participating Countries. FAO Land and Plant Nutrition Management Service. Available at [http://www.fao.org/nr/aboutnr/nrl/en/\#top] Accessed July 1, 2013.

Gachon C, Mingam A and Charrier B (2004). Real-time PCR: what relevance to plant studies? J. Exp. Bot. 55: 1445-1454.

Guénin S, Mauriat M, Pelloux J, Van WO, et al. (2009). Normalization of qRT-PCR data: the necessity of adopting a systematic, experimental conditions-specific, validation of references. J. Exp. Bot. 60: 487-493.

Gutierrez L, Mauriat M, Guénin S, Pelloux J, et al. (2008). The lack of a systematic validation of reference genes: a serious pitfall undervalued in reverse transcription-polymerase chain reaction (RT-PCR) analysis in plants. Plant Biotechnol. J. 6: 609-618.

Hernandez-Garcia CM, Martinelli AP, Bouchard RA and Finer JJ (2009). A soybean (Glycine max) polyubiquitin promoter gives strong constitutive expression in transgenic soybean. Plant Cell Rep. 28: 837-849.

Hoagland DR and Arnon DI (1938). The Water Culture Method for Growing Plants Without Soil. 2nd edn. California Agricultural Experiment Station, Davis.

Iqbal N, Umar S, Khan NA and Iqbal M (2014). A new perspective of phytohormones in salinity tolerance: regulation of proline metabolism. Environ. Exp. Bot. 100: 34-42.

Jain M, Nijhawan A, Tyagi AK and Khurana JP (2006). Validation of housekeeping genes as internal control for studying gene expression in rice by quantitative real-time PCR. Biochem. Biophys. Res. Commun. 345: 646-651.

Maas EV (1993). Testing Crops for Salinity Tolerance. In: Workshop on Adaptation of Plants to Soil Stresses (Maranville JW, Baligar BV, Duncan RR and Yohe JM, eds.). University of Nebraska, Lincoln, 234-247.

Marín-Guirao L, Sandoval-Gil JM, Ruíz JM and Sánchez-Lizaso JL (2011). Photosynthesis, growth and survival of the Mediterranean seagrass Posidonia oceanica in response to simulated salinity increases in a laboratory mesocosm system. Est. Coast. Shelf. Sci. 92: 286-296.

Munns R and Tester M (2008). Mechanisms of salinity tolerance. Annu. Rev. Plant Biol. 59: 651-681.

Muñoz-Bertomeu J, Cascales-Miñana B, Mulet JM, Baroja-Fernandez E, et al. (2009). Plastidial glyceraldehyde-3phosphate dehydrogenase deficiency leads to altered root development and affects the sugar and amino acid balance in Arabidopsis. Plant Physiol. 151: 541-558.

Nicot N, Hausman JF, Hoffmann L and Evers D (2005). Housekeeping gene selection for real-time RT-PCR normalization in potato during biotic and abiotic stress. J. Exp. Bot. 56: 2907-2914.

Panda SK and Khan MH (2009). Growth, oxidative damage and antioxidant responses in greengram (Vigna radiata $\mathrm{L}$.) under short-term salinity stress and its recovery. J. Agron. Crop. Sci. 195: 442-454.

Pareek A, Singla SL and Grover A (1998). Protein alterations associated with salinity, desiccation, high and low temperature stresses and abscisic acid application in seedlings of Pusa 169, a high-yielding rice (Oryza sativa L.). Curr. Sci. 75: 1023-1035.

Pfaffl MW, Horgan GW and Dempfle L (2002). Relative expression software tool (REST) for group-wise comparison and statistical analysis of relative expression results in real-time PCR. Nucleic Acids Res. 30: e36.

Rasmussen RP (2001). Quantification on the Light Cycler. In: Rapid Cycle Real-time PCR: Methods and Applications. 1st edn. (Meuer S, Wittwer CT and Nakagawara K, eds.). Springer Press, Heidelberg, 21-34.

SAS Institute Inc (2012). What’s New in SAS ${ }^{\circledR}$ 9.3. Cary, NC: SAS Institute Inc.

Silver N, Best S, Jiang J and Thein SL (2006). Selection of housekeeping genes for gene expression studies in human reticulocytes using real-time PCR. BMC Mol. Biol. 7: 33.

Sun CW, Griffen S and Callis J (1997). A model for the evolution of polyubiquitin genes from the study of Arabidopsis thaliana ecotypes. Plant Mol. Biol. 34: 745-758.

Tester M and Davenport R (2003). Na+ tolerance and Na+transport in higher plants. Ann. Bot. 91: 503-527.

Tong Z, Gao Z, Wang F, Zhou J, et al. (2009). Selection of reliable reference genes for gene expression studies in peach using real-time PCR. BMC Mol. Biol. 10: 71.

Vandesompele J, De PK, Pattyn F, Poppe B, et al. (2002). Accurate normalization of real-time quantitative RT-PCR data by geometric averaging of multiple internal control genes. Genome Biol. 3: Research 0034.

Walia H, Wilson C, Condamine P, Liu X, et al. (2005). Comparative transcriptional profiling of two contrasting rice genotypes under salinity stress during the vegetative growth stage. Plant Physiol. 139: 822-835.

Wang Y and Frei M (2011). Stressed food-the impact of abiotic environmental stresses on crop quality. Agric. Ecosyst. Environ. 141: 271-286.

Wang Y, Yu K, Poysa V, Shi C, et al. (2012). Selection of reference genes for normalization of qRT-PCR analysis of differentially expressed genes in soybean exposed to cadmium. Mol. Biol. Rep. 39: 1585-1594.

Whittaker DJ and Triplett BA (1999). Gene-specific changes in alpha-tubulin transcript accumulation in developing cotton fibers. Plant Physiol. 121: 181-188.

Zhang Z and Hu J (2009). Development and validation of endogenous reference genes for expression profiling of medaka (Oryzias latipes) exposed to endocrine disrupting chemicals by quantitative real-time RT-PCR. Toxicol. Sci. 95: 356-368.

Genetics and Molecular Research 14 (1): 2384-2398 (2015) 